\title{
Cellulose/Guar Gum Hydrogel Microspheres as a Magnetic Anticancer Drug Carrier
}

\author{
Yanli Li, ${ }^{\text {a,b }}$ Yucheng Feng, ${ }^{\text {a, }}$ Jun Jing, , and Fei Yang*,a,b \\ A novel magnetic anticancer drug carrier based on cellulose, guar gum, \\ and $\mathrm{Fe}_{3} \mathrm{O}_{4}$ hydrogel microspheres was synthesized by chemical \\ crosslinking. These microspheres were crosslinked with epoxy \\ chloropropane and loaded with 5-fluorouracil (5-fu). The effect of the ratio \\ of cellulose to guar gum on bead size, drug loading, and in vitro release \\ behaviors were investigated. The influence of the magnetic content on \\ drug loading and in vitro release behaviors were also evaluated. The \\ magnetic hydrogel microspheres were characterized via an optical \\ microscope, Fourier transform infrared spectroscopy, swelling behavior \\ analysis, vibrating sample magnetometer, and ultraviolet absorption \\ spectroscopy. The results showed that as the ratio of cellulose to guar gum \\ increased from 3:1 to 5:1, the particle size increased from 395 to 459 um. \\ Moreover, the drug loading capacity, encapsulation efficiency, and in vitro \\ release behavior were influenced by the ratio of cellulose/guar gum and \\ $\mathrm{Fe}_{3} \mathrm{O}_{4}$ content. Finally, the $\mathrm{Fe}_{3} \mathrm{O}_{4}$ particle had an adsorption effect on the \\ drug, thereby reducing the maximum cumulative release.
}

Keywords: Cellulose; Guar gum; $\mathrm{Fe}_{3} \mathrm{O}_{4}$ nanoparticle; Hydrogel microsphere; Drug controlled release

Contact information: a: State Key Laboratory of Pulp and Paper Engineering, South China University of Technology, Guangzhou 510640, China; b: United Lab of Plant Resources Chemistry and Chemical

Engineering, South China University of Technology, Guangzhou 510640, China;

* Corresponding author: yangfei@scut.edu.cn

\section{INTRODUCTION}

Currently, cancer is one of the most life-threatening diseases worldwide, especially in China where cancer incidence and mortality has continued to increase and has become a major public health problem (Chen et al. 2016). The treatment for cancer includes surgery, radiation, and chemotherapy. Chemotherapy is one of the most useful treatments for cancer. However, the improvement in quality of life and increasing safe awareness assure that high quality and safe drug therapies are a priority for policymakers and multidisciplinary scientists. Controlled drug delivery technology has had a more dominant role in recent years due to its advantages compared to the conventional medicine system, including improved efficiency and reduced dosage (Uhrich et al. 1999; Babu et al. 2007). Drug carriers have an important role in the drug release system and are a main factor in affecting drug efficacy (Uekama and Otagiri 1987). Polymeric hydrogels are cross-linked hydrophilic materials that have a three-dimensional network structure and can absorb large quantities of water without dissolving (O'Connor and Gehrke 2015; Liu et al. 2009). In recent years, much attention has been focused on hydrogel microspheres for the delivery of water-solution drugs due to their outstanding characteristics such as excellent waterabsorption, water-retention, and slow-release (Korsmeyer et al. 1983; Liu et al. 2006a; Karaaslan et al. 2010).

Biopolymeric resources are promising feedstocks to produce sustainable products (Nurunnabi et al. 2015; Aravamudhan et al. 2016; Shaghaleh et al.2018). 
Cellulose is the most abundant natural polymer on Earth (Bledzki and Gassan 1999; Fan et al. 2017). Because cellulose has an abundant number of hydroxyl groups, it can be used to prepare hydrogels easily with fascinating structures and properties (Chang and Zhang 2011; Xu et al. 2018). For example, previous work exploited carboxymethyl cellulose (CMC) beads via a liquid curing method in the presence of trivalent ferric ions, and epicholorohydrin was covalently bonded to the CMC beads (Yakup 2015). Cellulose (or its derivatives) blended with other polymers is an extremely attractive, inexpensive, and advantageous method to obtain new structural materials (Bajpai et al. 2008), such as chitosan (Nan and Bai 2005), starch (Faroongsarng and Sukonrat 2008), and polyvinyl alcohol (Salmawi 2007; Chang et al. 2010). Guar gum is one of the most abundant natural polysaccharides in the world, consisting of a 1,4- $\beta$-D-mannose backbone and 1,6- $\alpha$-D-galactose side chain, with a ratio of galactose/mannose of 1:2 (Sinha and Kumria 2001; Li et al. 2008). It has been suggested as a vehicle for oral controlled release purposes and for colon targeting due to its biodegradability and biocompatibility (Huang et al. 2007). However, to the authors' knowledge, there have been few reports on the investigation of cellulose blended with guar gum microspheres.

Recently, magnetic nanoparticles have gained attention because of their unique features (Rani et al. 2010; Fan et al. 2011). They can be used in medical applications, such as drug targeting for drug control release and targeted release, especially for cancer therapy (Liu et al. 2006b). This innovative strategy for targeted drug delivery consists of coupling the drug to magnetic nanoparticles that can be guided to the target by means of external magnetic fields (Barbucci et al. 2012). In the present paper, the objective is to prepare a magnetic hydrogel microsphere, consisting of cellulose, guar gum, and $\mathrm{Fe}_{3} \mathrm{O}_{4}$, while the microspheres were located with 5-fluorouracil (5-fu). The effect of the ratio of cellulose to guar gum on bead size and drug loading as well as the in vitro release behaviors were investigated. The influence of magnetic content on drug loading and in vitro release behaviors were also studied. The magnetic hydrogel microspheres were characterized using an optical microscope, Fourier transform infrared spectroscopy (FTIR), and swelling behavior, vibrating sample magnetometer (VSM) to investigate the shape synthesis. Additionally, ultraviolet (UV) absorption spectroscopy was performed to evaluate the drug loading and release.

\section{EXPERIMENTAL}

\section{Materials}

Jute pulp was supplied by China Tobacco Mauduit (Guangdong, China). Guar gum was bought from Wuhan Shengruiyuan Biotechnology Co., Ltd. (Wuhan, China), Liquid paraffin, epoxy chloropropane, sodium hydroxide, and urea were supplied by Guangzhou Congyuan Instrument Corporation (Guangzhou, China). Iron vitriol and anhydrous ferric chloride were bought from Tianjin Damao Chemical Reagent Factory (Guangzhou, China) and 5-fluorouracil (5-fu) was supplied by Aladdin Reagent Co., Ltd. (Shanghai, China). All of the chemical reagents were of analytical grade without further purification. 


\section{Methods}

Preparation of cellulose/guar gum hydrogel microspheres

Jute pulp was dissolved in a $\mathrm{NaOH} /$ urea aqueous solution at a low temperature to form a cellulose solution with a concentration of $2 \mathrm{wt} \%$ as previously described (Qin et al. 2013). Guar gum was dissolved in water by stirring overnight to form a guar gum solution with a concentration of $1 \mathrm{wt} \%$. The gel beads were produced in a $250-\mathrm{mL}$ round-bottom flask equipped with a stirrer. Liquid paraffin $(100 \mathrm{~mL})$ in a continuous phase was added to provide a reaction environment and Tween 80 was added as a $0.1 \mathrm{~mL} / \mathrm{mL}$ mixed solution as dispersants. Then, the mixture of cellulose and guar gum was poured into the continuous phase while it was being stirred at a speed of $800 \mathrm{r} / \mathrm{min}$. When the mixed solution was dispersed into droplets in liquid paraffin, epoxy chloropropane was added as a $0.1 \mathrm{~mL} / \mathrm{mL}$ mixed solution. The solution was kept at $30^{\circ} \mathrm{C}$ for $30 \mathrm{~min}$ and then heated to $60{ }^{\circ} \mathrm{C}$. Five hours later, the reaction was stopped, and the gel beads were obtained. The microspheres were then frozen and freeze-dried in a lyophilizer (FD5-2.5; Gold SIM, Los Angeles, USA) $\left(-58^{\circ} \mathrm{C}, 0.22 \mathrm{mbar}\right)$ for $48 \mathrm{~h}$ before further analysis.

\section{Preparation of cellulose/guar gum/Fe $\mathrm{O}_{4}$ hydrogel microspheres}

The $\mathrm{Fe}_{3} \mathrm{O}_{4}$ magnetic fluid was prepared via chemical coprecipitation of iron vitriol and anhydrous ferric chloride solution $(0.25 \mathrm{~mol} / \mathrm{L})$ with ammonia as the precipitant (Deng et al. 2003). To the resultant suspension, the $\mathrm{Fe}_{3} \mathrm{O}_{4}$ magnetic fluid was washed by deionized water until $\mathrm{pH}=7$ and was then stored in $50 \mathrm{~mL}$ of alcohol. The obtained magnetic nanoparticles were added to a cellulose/guar gum mixture during the process of the polymerization reaction. The magnetic hydrogel microspheres were treated with $\mathrm{Fe}_{3} \mathrm{O}_{4}$ magnetic fluid with different volumes of 0.2 $\mathrm{mL}, 0.4 \mathrm{~mL}$, and $0.6 \mathrm{~mL}$ and were coded as $\mathrm{M} 1, \mathrm{M} 2$, and $\mathrm{M} 3$, respectively. The samples that were loaded with $\mathrm{Fe}_{3} \mathrm{O}_{4}$ were calcined at $600{ }^{\circ} \mathrm{C}$ for $5 \mathrm{~h}$ to obtain iron oxide. Then, the content of $\mathrm{Fe}_{3} \mathrm{O}_{4}$ loaded into the hydrogel was calculated from the $\mathrm{Fe}_{2} \mathrm{O}_{3}$.

\section{Morphology of hydrogel microspheres}

An optical microscope (SZX12; Olympus, Tokyo, Japan) was used to observe the size of the gel beads. The bead size was the average size determined by measuring 200 samples of beads (O'Connor and Gehrke 2015). 


\section{Fourier transform infrared spectroscopy}

The FTIR spectral measurements were performed using a Nicolet FTIR spectrometer (Nicolet Nexus 670; Nicolet Instrument Technologies, Inc., Madison, WI, USA) to confirm the presence of cross-linking in the cellulose-guar gum gel beads. The blended particles were finely ground with $\mathrm{KBr}$ to prepare the pellets, and the spectra were scanned between 600 and $3700 \mathrm{~cm}^{-1}$.

\section{Swelling behavior analysis}

Swelling experiments were conducted in distilled water at $25{ }^{\circ} \mathrm{C}$. The weighed mass of dry microspheres were dipped in the distilled water. After preset time intervals, the sample was blotted with filter paper to remove excess water from the hydrogel surface and the sample was weighed. The swelling ratio (S) was calculated according to,

$$
S=\frac{W_{t}-W_{d}}{W_{d}}
$$

where $W_{\mathrm{t}}(\mathrm{g})$ and $W_{\mathrm{d}}(\mathrm{g})$ are the weights of microsphere at any time (min) and the initial weight of the dry gels, respectively.

\section{Magnetic properties analysis}

The magnetic properties of the microspheres were measured with a vibrating sample magnetometer (VSM, Lake Shore, Columbus, OH, USA) at $25^{\circ} \mathrm{C}$, and the hysteresis loop was obtained in a magnetic field that was varied from 1.0 to $+1.0 \mathrm{~T}$.

\section{Drug loaded into hydrogel microspheres}

A sample of $20 \mathrm{mg}$ of 5-fu was dissolved into the mixture of cellulose and guar gum (mixture of cellulose, guar gum, and $\mathrm{Fe}_{3} \mathrm{O}_{4}$ magnetic fluid) during the heat-initiated free radical polymerization process. The syntheses of composite microsphere and drug loaded process were presented in Fig. 1. After polymerization, drug-loaded hydrogels were frozen and then freeze-dried in a lyophilizer $\left(-58{ }^{\circ} \mathrm{C}\right.$, 0.22 mbar) for $48 \mathrm{~h}$. The drug-loading content (Q) and encapsulation efficiency (EE) were determined using a UV-spectrophotometer (UV-2600, Shimadzu, Suzhou, China) at $265 \mathrm{~nm}$.

$$
\begin{aligned}
& E E(\%)=\left(\frac{W_{a}}{W_{t}}\right) \times 100 \\
& Q(\%)=\left(\frac{W_{a}}{W}\right) \times 100
\end{aligned}
$$

where $W_{\mathrm{t}}$ is the total amount $(\mathrm{g})$ of 5 -fu employed and $W_{\mathrm{a}}$ is $W_{\mathrm{t}}$ minus the amount $(\mathrm{g})$ of unloaded 5-fu and $W$ is the weight (g) of microsphere.

\section{In vitro release}

A sample of $20 \mathrm{mg}$ of drug-loaded cellulose/guar gum (cellulose/guar gum/ $\mathrm{Fe}_{3} \mathrm{O}_{4}$ ) hydrogel microspheres were dispersed in $20 \mathrm{~mL}$ of artificial simulation intestinal fluid, and then was stirred at $100 \mathrm{rpm}$ at $37^{\circ} \mathrm{C}$. The drug release behavior from the microspheres was studied in the intestinal fluid. At regular intervals of time, $2 \mathrm{~mL}$ of release media was removed and replaced by fresh release media. The 
concentration of 5-fu released was determined using a UV-spectrophotometer (UV2600; Shimadzu, Suzhou, China) at $265 \mathrm{~nm}$.

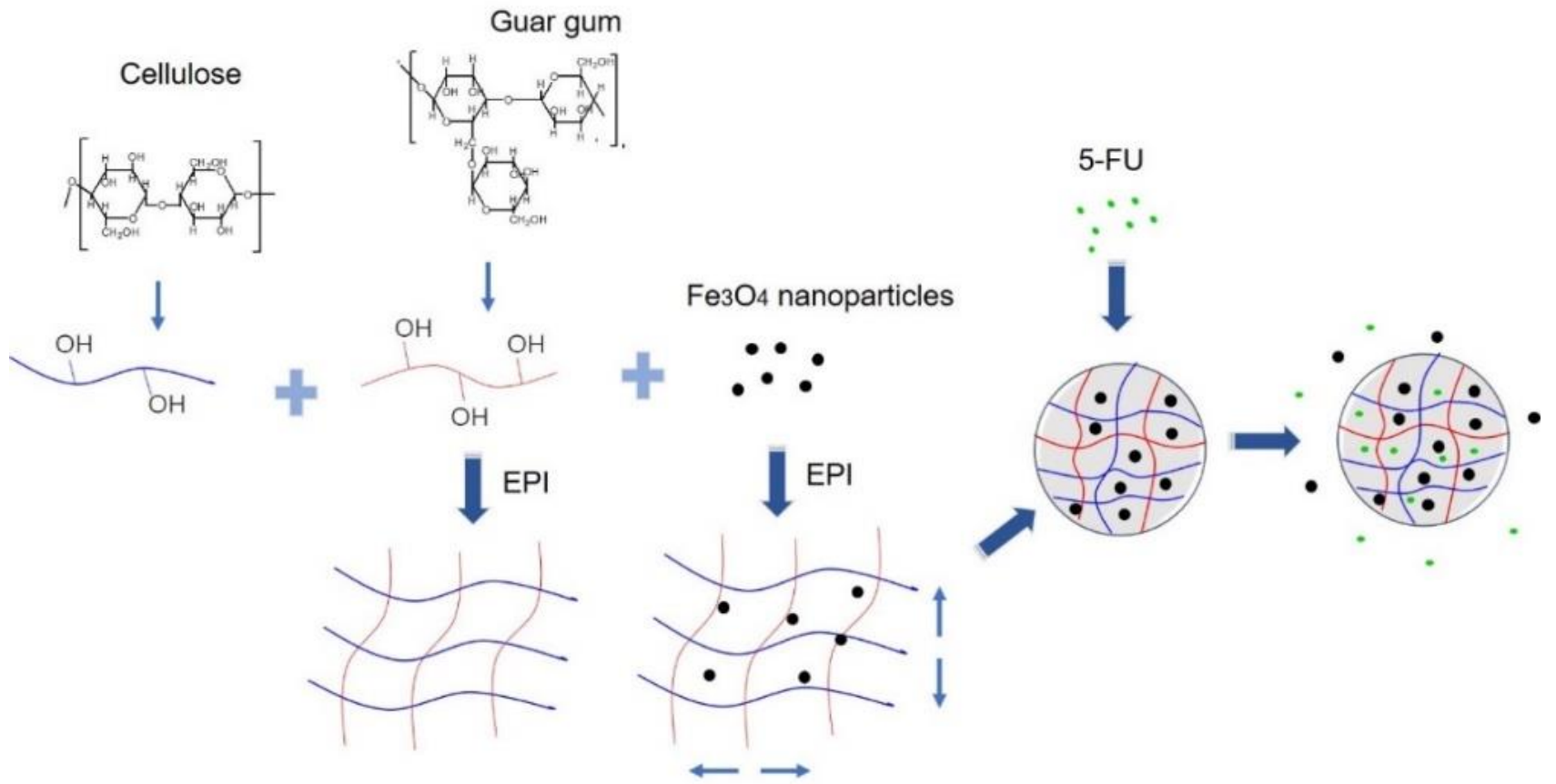

Fig. 1. Preparation of the drug-loaded cellulose/guar gum $/ \mathrm{Fe}_{3} \mathrm{O}_{4}$ hydrogel nanosphere

\section{RESULTS AND DISCUSSION}

\section{Microscopic Study}

The microspheres prepared by different methods had different particle sizes, as shown in Table 1 and Fig. 2.

Table 1. Results of Particle Size of Different Ratios of Cellulose to Guar Gum

\begin{tabular}{|c|c|c|c|c|c|}
\hline Samples & $\begin{array}{c}\text { Ratio of Oil to } \\
\text { Mixture }\end{array}$ & $\begin{array}{c}\text { Ratio of } \\
\text { Cellulose to } \\
\text { Guar Gum }\end{array}$ & $\begin{array}{c}\text { Particle Size } \\
\text { (um) }\end{array}$ & $\begin{array}{c}\text { Drug Loading } \\
(\%)\end{array}$ & $\begin{array}{c}\text { Encapsulation } \\
\text { Efficiency (\%) }\end{array}$ \\
\hline C-1 & $8: 1$ & - & 523 & 1.27 & 23.8 \\
\hline CG-1 & $8: 1$ & $5: 1$ & 459 & 5.3 & 89.1 \\
\hline CG-2 & $8: 1$ & $4: 1$ & 425 & 3.5 & 68.8 \\
\hline CG-3 & $8: 1$ & $3: 1$ & 395 & 1.5 & 28.9 \\
\hline
\end{tabular}



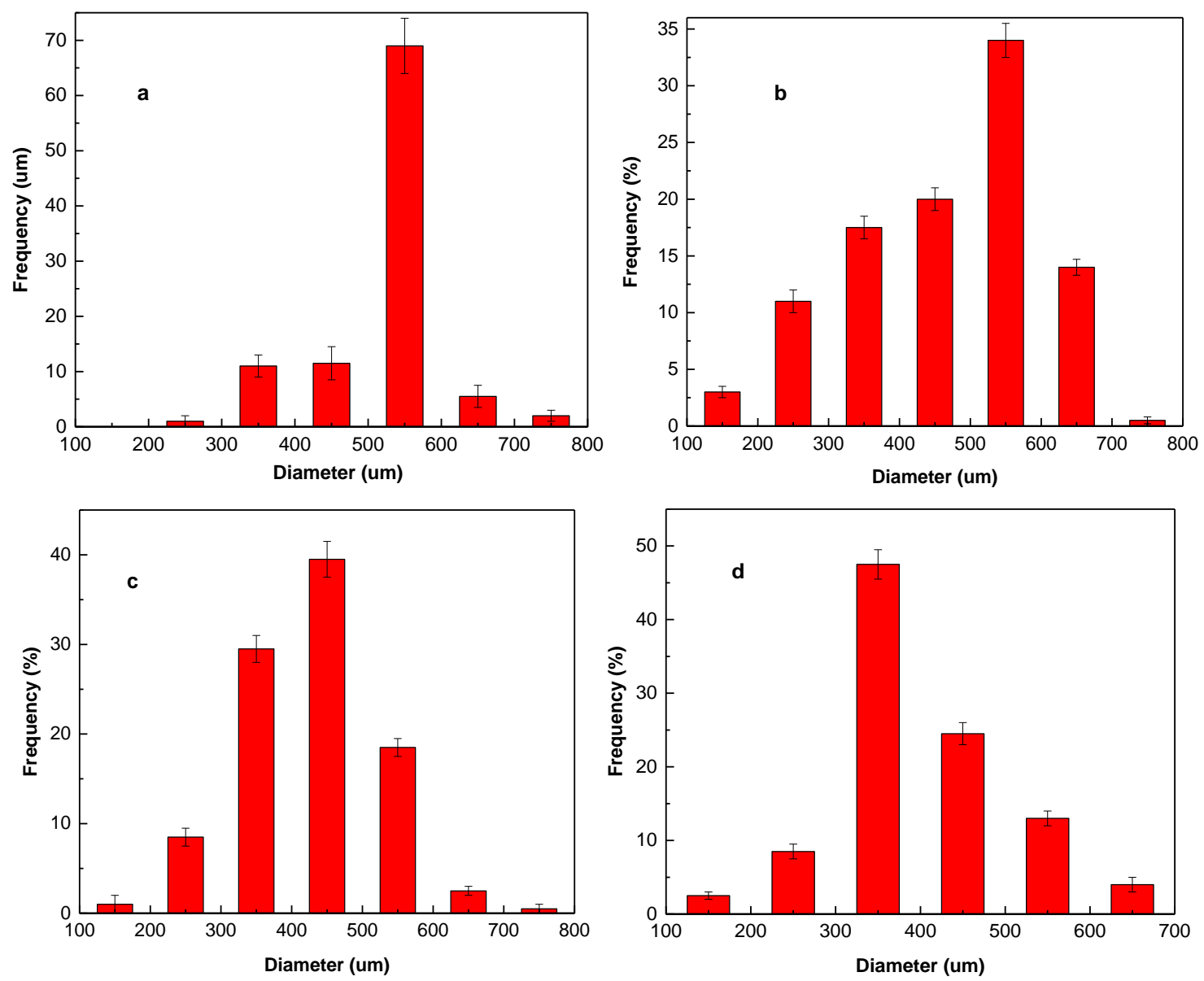

Fig. 2. The size distribution of gel beads. (a) C-1, (b) CG-1, (c) CG-2, (d) CG-3

Results indicated that gel bead diameter was influenced by the guar gum content of the microsphere. It is known that the particle size of the pristine cellulose was higher than those of the cellulose/guar gum composite microspheres. Table 1 also shows that as the ratio of cellulose to guar gum increased from 3:1 to 5:1, the average size increased from 359 to 459 um; this change can be seen by size distribution of gel beads (Fig. 2). The size distributions generally could be fitted to the Gaussian distribution. With an increase of guar gum content, the size of beads moves toward to lower size. As the amount of guar gum in the microsphere increased, the interfacial viscosity of the polymer droplets in the emulsion also increased. Because the number of free sites available for cross-linking was more with the increasing amount of guar gum, the size of the microspheres also decreased. The optical microscope micrographs of $\mathrm{C}-1$ are shown in Fig. 3. 


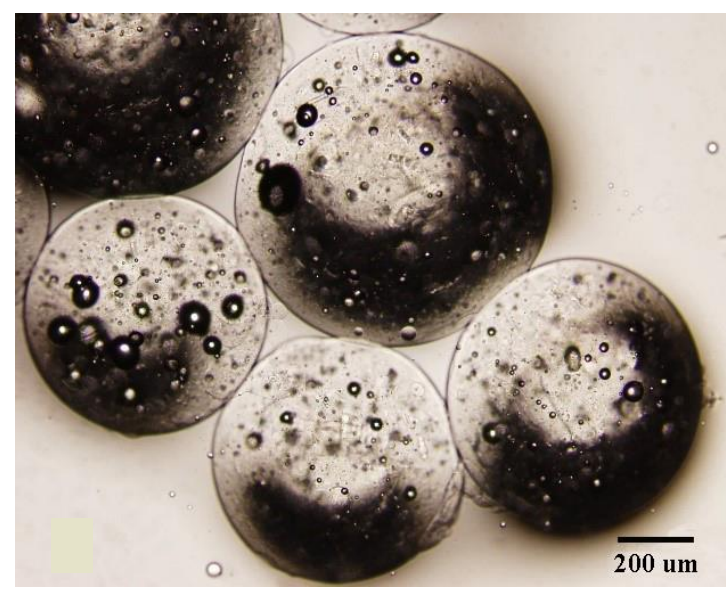

Fig. 3. Optical microscope micrographs of C-1

\section{FTIR Spectroscopy Analysis}

IR spectra of composite hydrogel are depicted in Fig. 4.

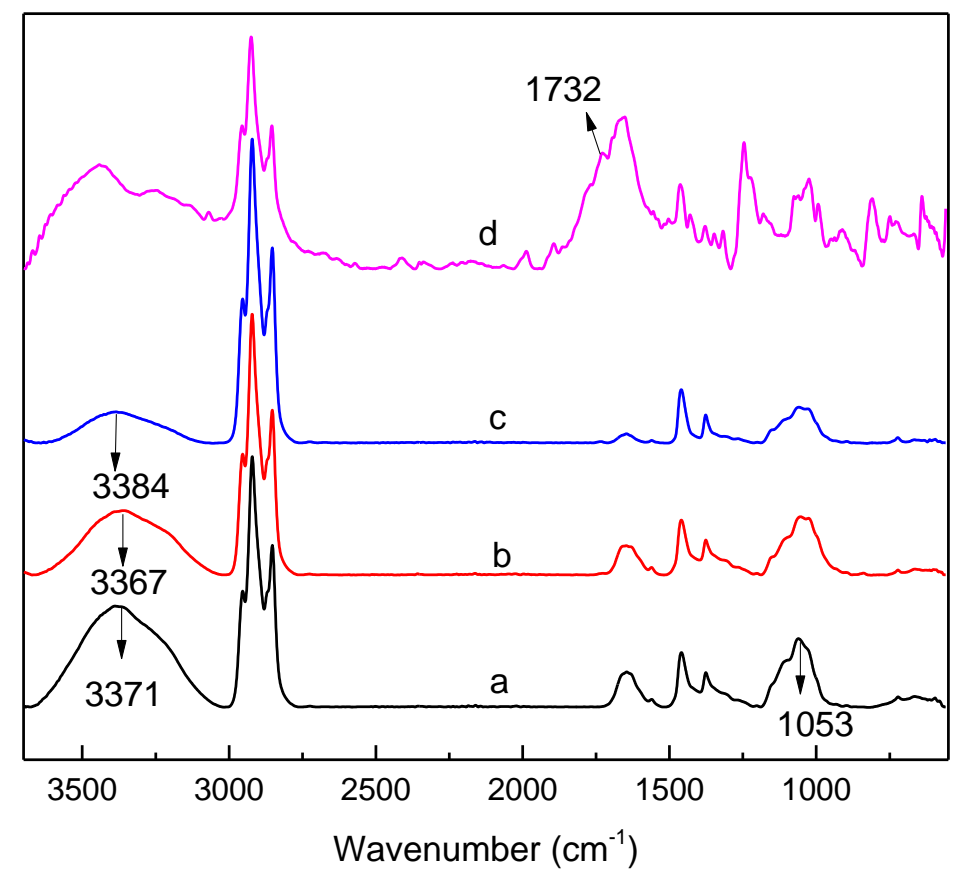

Fig. 4. FTIR spectra of gel beads: (a): CG-1 (Cellulose/guar gum = 5:1), (b): CG-3 (Cellulose/guar gum = 3:1), (c): C-1 (pure cellulose) and (d) DC-1 (Drug loaded C-1)

There were strong absorption peaks at about 3384 to $3367 \mathrm{~cm}^{-1}$ in Fig. 4 (a, b and c), attributed to the stretching of $-\mathrm{O}-\mathrm{H}$ from gel beads. In addition, the peak at $1053 \mathrm{~cm}^{-1}$ was assigned to the $\mathrm{C}-\mathrm{O}-\mathrm{C}$, which suggests the cross-linking reaction of cellulose or guar gum with epoxy chloropropane. As Fig. 4 shows, the vibration peak of -O-H was stronger and exhibited a shift towards a slightly lower wavenumber direction with increased guar gum content relative to cellulose. This suggested that cellulose/guar gum was well mixed and led to noticeable changes in the interaction between the molecules. In Fig. 4 (d), a significant new peak appears at $1732 \mathrm{~cm}^{-1}(\mathrm{C}=\mathrm{O}$ stretching $)$ of carbonyl group of 5-Fu; this result indicated that the 5 -fu were loaded with $\mathrm{C}-1$. 


\section{Swelling Behavior Analysis}

The swelling kinetics curves of samples in distilled water at $25{ }^{\circ} \mathrm{C}$ were displayed in Fig. 5. As we can see, compared with $\mathrm{CG}$ composited hydrogel, pristine cellulose hydrogel has much lower swelling ratio. With an increase of guar gum content, the equilibrium swelling ratios of the hydrogels increases from 14.0 to $20.1 \mathrm{wt} \%$. The more guar gum content, the more available free volume of the expanded polymer matrix and availability of group such as $-\mathrm{OH}$ able to form hydrogen bonds with water. As a consequence, compared with the same hydrogels with lower guar gum content, high guar gum content hydrogel showed a higher swelling ratio.

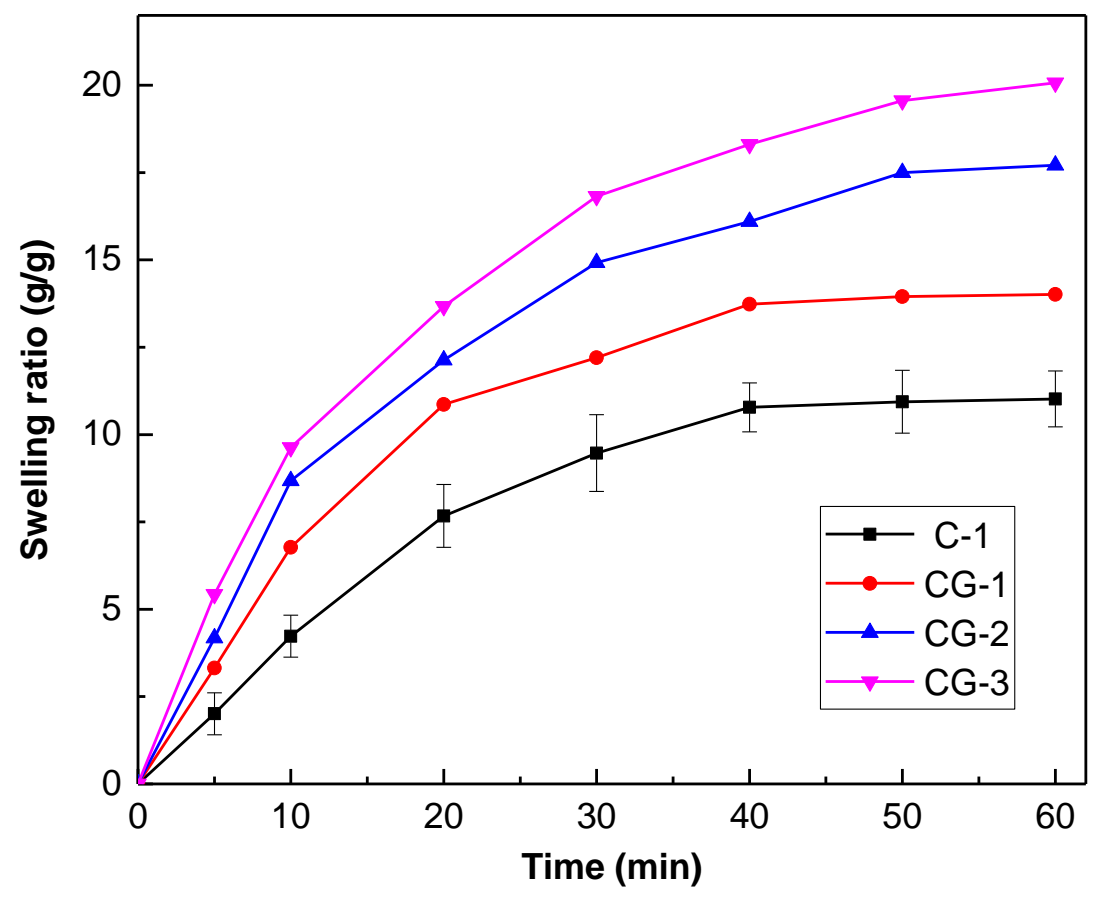

Fig. 5. Swelling kinetics curves of C-1, CG-1, CG-2, and CG-3 in distilled water at $25^{\circ} \mathrm{C}$

\section{Magnetic Properties}

Figure 6 shows the images of M1, M2, and M3 in a magnetic field. As can be seen, the samples could align in the magnetic field. Also, the magnetic response of hydrogel microsphere was more sensitive with the increasing of $\mathrm{Fe}_{3} \mathrm{O}_{4}$ content. This revealed that the magnetic hydrogel microsphere could move directionally by introducing a magnetic field. Therefore, the goal of site-specific drug delivery of the magnetic beads loaded drug can be achieved by using an external magnetic field.

The magnetization of M1, M2, and M3 as a function of the magnetic field at $298 \mathrm{~K}$ is shown in Fig. 6. As can be seen, their magnetization increased with an increase of the magnetic field. This clearly shows that they exhibited an extremely small hysteresis loop and low coercivity, which demonstrated the superparamagnetism of the particles. The result indicated that the magnetic composite microspheres possessed good magnetic property and thus, showed promise in biomedical applications. 


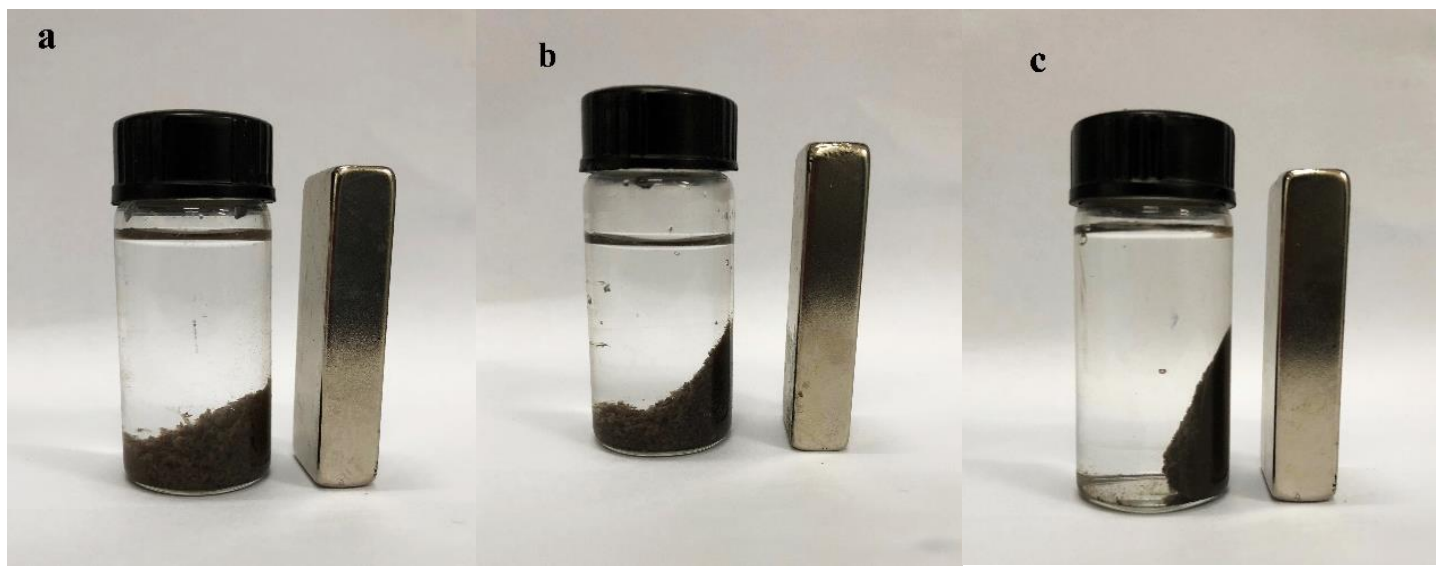

Fig. 6. Photos of $M 1, M 2$, and $M 3$ on in a magnetic field. (a) M1, (b) $M 2$, (c) $M 3$

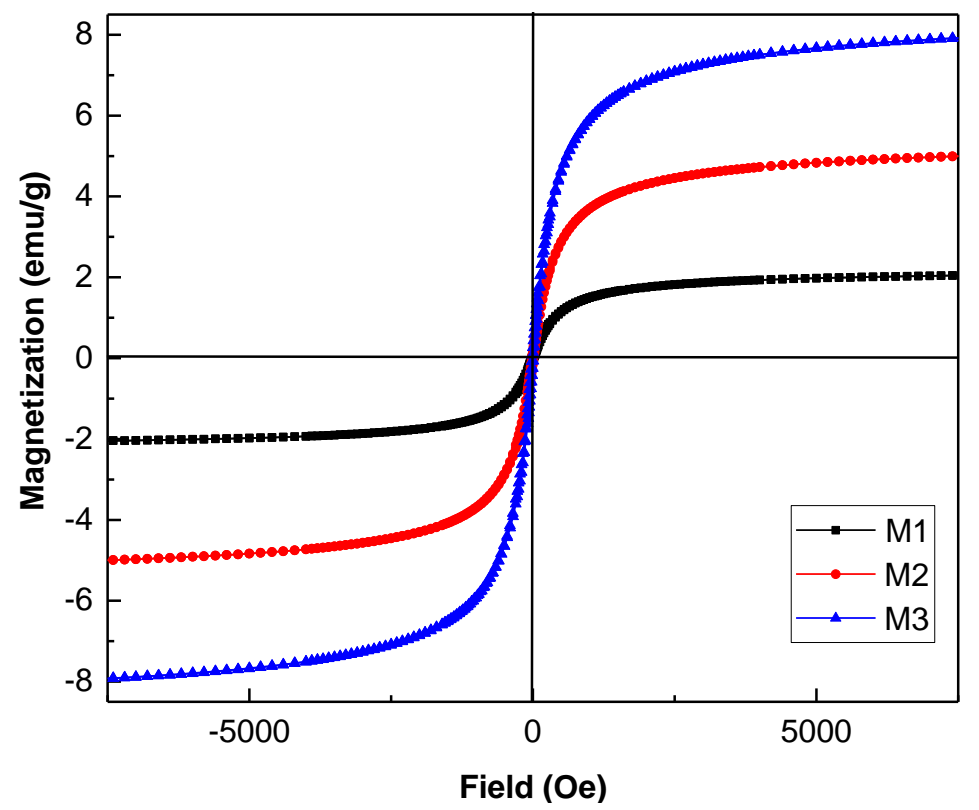

Fig. 7. The magnetic hysteresis loops of the microspheres $\mathrm{M} 1, \mathrm{M} 2$, and $\mathrm{M} 3$ at $25^{\circ} \mathrm{C}$

\section{Effect of Ratio of Cellulose to Guar Gum}

The effect of the ratio of cellulose to guar gum on 5-fu loading and release behavior was studied. The results of the drug loading and encapsulation efficiency in Table 1 showed an increasing trend with an increasing ratio of cellulose to guar gum. A drug loading of $1.27 \%$ and encapsulation efficiency of $23.8 \%$ were observed for pristine cellulose microspheres. There was a lesser amount of 5-fu in the cellulose microspheres due to the cellulose hydrogel having less cross-links and a bigger free volume space, thereby causing drug run off.

When the ratio of cellulose/guar gum was 5:1, 4:1, and 3:1, the 5-fu loading was $5.3,3.5$, and $1.5 \%$, and the encapsulation efficiency increased to $89.1,68.8$, and $28.9 \%$, respectively (Table 1). These were higher than the numbers reported in the cellulose hydrogel microspheres. By increasing the guar gum content of hydrogel, the cross-link points and density increased, thereby reducing the drug loading into gel beads runoff. The results can also indicated that guar gum with more -OH group contributed to the 5-fu adsorption through hydrogen bonding. However, the microspheres became rigid and the 
free volume space decreased with increased guar gum content. These tendencies resulted in a decrease of the 5-fu loading and encapsulation efficiency.

The release behavior of the gel beads was also examined. Figure 8 shows that the guar gum content of the microspheres strongly affected the drug release behavior. When the guar gum content increased from 0 to $33.3 \%$, the cumulative drug release decreased from 76.2 to $50.2 \%$ in a $36-\mathrm{h}$ period. The release rate also was clearly reduced. In general, the drug release behavior from the hydrogel was driven by two forces: diffusion effect and degradation or erosion of the hydrogels (Bromberg and Ron 1998; Wang et al. 2010). The performance of this drug release indicated that a higher guar gum content hydrogel had a larger amount of water absorbed and displayed a swelling behavior. This can be confirmed from Fig. 5. As a result, by controlling guar gum content, the drug controlled release can be achieved.

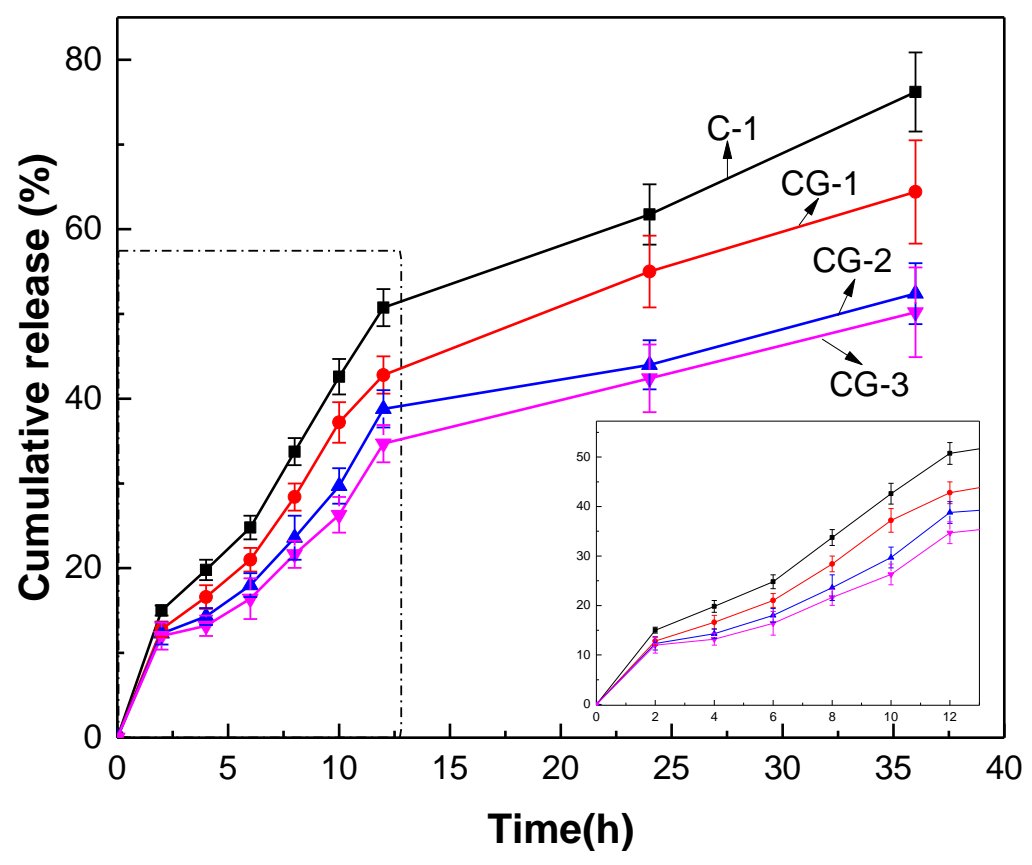

Fig. 8. The effect of guar gum content on drug cumulative release

\section{Effect of Magnetic Content of Hydrogel Microsphere}

The loading behavior of 5-fu onto the hydrogel microspheres with different magnetic content was performed, and its loading and encapsulation efficiency profile are displayed in Fig. 9. It was found that the $\mathrm{Fe}_{3} \mathrm{O}_{4}$ content had a great effect on the loading and encapsulation of 5-fu. When the $\mathrm{Fe}_{3} \mathrm{O}_{4}$ content increased from 0 to $30 \%$, the drug loading and encapsulation efficiency decreased from 5.3 to $2.7 \%$ and 89.1 to $50 \%$, respectively. 


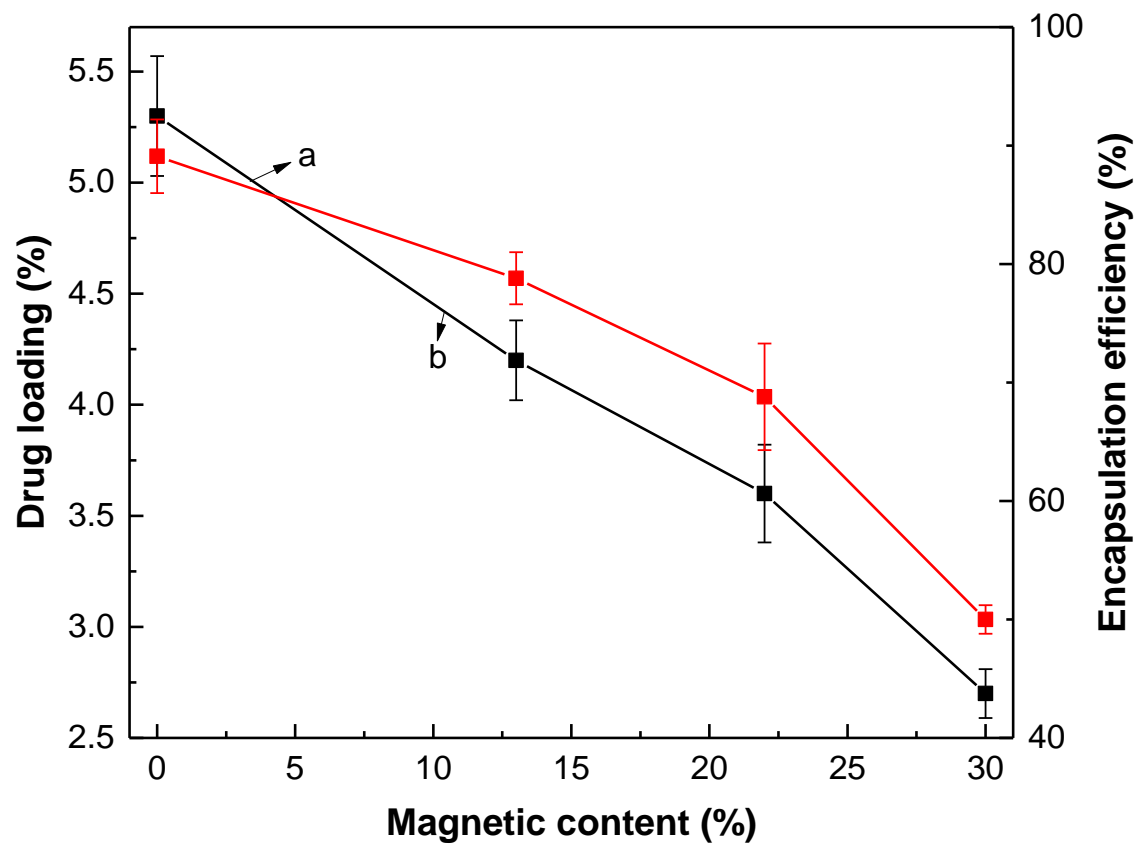

Fig. 9. The effect of magnetic content of hydrogel on drug loading (a) and encapsulation efficiency (b)

The time dependence of 5-fu release from the drug-loading hydrogel microspheres with different magnetic content was investigated. The obtained data was plotted in Fig. 10.

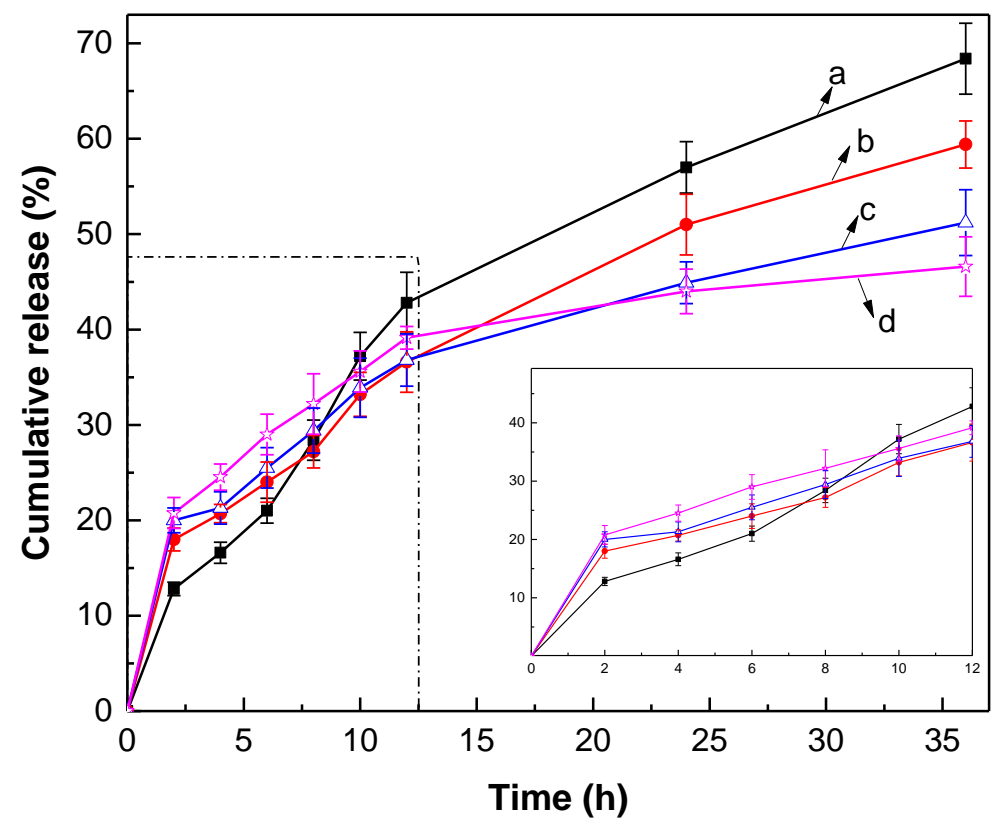

Fig. 10. The effect of magnetic content on drug cumulative release; (a) $0 \%$, (b) $13 \%$, (c) $23 \%$, and (d) $30 \%$

Figure 10 shows that the 5-fu maximum cumulative release and release rate noticeably slowed down when the $\mathrm{Fe}_{3} \mathrm{O}_{4}$ content increased from 0 to $30 \%$ and the cumulative release reached $68.4 \%, 59.4 \%, 51.2 \%$, and $46.6 \%$ in a $36-\mathrm{h}$ time period when 
the $\mathrm{Fe}_{3} \mathrm{O}_{4}$ content was $0 \%, 13 \%, 23 \%$, and $30 \%$, respectively. The results indicated that the $\mathrm{Fe}_{3} \mathrm{O}_{4}$ content played an important role in reducing the cross-linking concentration such that the microspheres became slack (Gao et al. 2014); thereby an increase in the release rate was observed. However, the cumulative release of the drug from gel beads was also prevented by the adsorption of $\mathrm{Fe}_{3} \mathrm{O}_{4}$ (Wang et al. 2017). These tendencies resulted in the decrease of the maximum release in the time of $36 \mathrm{~h}$.

\section{CONCLUSIONS}

1. Compared to the cellulose/guar gum hydrogel microspheres, the particle size of the pristine cellulose was higher. As the ratio of cellulose to guar gum increased from 3:1 to $5: 1$, the particle size increased from 395 to $495 \mathrm{um}$.

2. The ratio of cellulose to guar gum had a great influence on the drug loading and release behaviors. When the ratio of cellulose/guar gum were 5:1, 4:1, and 3:1, the 5-fu loading was $5.3,3.5$, and $1.5 \%$, and the encapsulation efficiency increased to $89.1 \%, 68.8$, and $28.9 \%$, respectively. Moreover, when the ratio of cellulose to guar gum increased from 3 to $5: 1$, the cumulative drug release decreased from 76.2 to $50.2 \%$ in a $36-\mathrm{h}$ period.

3. It was indicated that $\mathrm{Fe}_{3} \mathrm{O}_{4}$ content strongly affected drug loading and release behaviors. When the $\mathrm{Fe}_{3} \mathrm{O}_{4}$ content increased from 0 to $30 \%$, the drug loading and encapsulation efficiency decreased from 5.3 to $2.7 \%$ and 89.1 to $50 \%$, respectively. Additionally, the cumulative release reached $68.4 \%, 59.4 \%, 51.2 \%$, and $46.6 \%$ in a $36-\mathrm{h}$ time period when the $\mathrm{Fe}_{3} \mathrm{O}_{4}$ content was $0 \%, 13 \%, 23 \%$, and $30 \%$, respectively.

\section{ACKNOWLEDGMENTS}

The authors are grateful for the support of the National Natural Science Foundation of China (31600471), the Fundamental Research Funds for the Central Universities (2017ZD089 and 2017MS087), the Science and Technology Plan Projects of Guangzhou City (Grant No. 201504010013), the Guangdong Province Science Foundation for Cultivating National Engineering Research Center for Efficient Utilization of Plant Fibers (2017B090903003), and the State Key Laboratory of Pulp and Paper Engineering (201833).

\section{REFERENCES CITED}

Aravamudhan, A., Ramos, D. M., Jenkins, N. A., Dyment, N. A., Sanders, M. M., Rowe, D. W., and Kumbar, S. G. (2016). "Collagen nanofibril self-assembly on a natural polymeric material for the osteoinduction of stem cells in vitro and biocompatibility in vivo," RSC Adv. 2016(84), 80851-80866. DOI: 10.1039/C6RA15363A

Babu, V. R., Sairam, M., Hosamani, K. M., and Aminabhavi, T. M. (2007). "Preparation of sodium alginate-methylcellulose blend microspheres for controlled release of nifedivine," Carbohyd. Polym. 69(2), 241-250. DOI: 10.1016/j.carbpol.2006.09.027 
Bajpai, A. K., Shukla, S. K., Bhanu, S., and Kankane, S. (2008). "Responsive polymers in controlled drug delivery," Prog. Polym. Sci. 33(11), 1088-1118. DOI: 10.1016/j.progpolymsci.2008.07.005

Barbucci, R., Giani, G., Fedi, S., Bottari, S., and Casolaro, M. (2012). "Biohydrogels with magnetic nanoparticles as crosslinker: Characteristics and potential use for controlled antitumor drug-delivery," Acta Biomater. 8(12), 4244-4252. DOI: 10.1016/j.actbio.2012.09.006

Bledzki, A. K., and Gassan, J. (1999). "Composites reinforced with cellulose based fibres," Prog. Polym. Sci. 24(2), 221-274. DOI: 10.1016/S0079-6700(98)00018-5

Bromberg, L. E., and Ron, E. S. (1998). "Temperature-responsive gels and thermogelling polymer matrices for protein and peptide delivery," Adv. Drug Deliver. Rev. 31(3), 197-221. DOI: 10.1016/S0169-409X(97)00121-X

Chang, C., Lue, A., and Zhang, L. (2010). "Effects of crosslinking methods on structure and properties of cellulose/PVA hydrogels," Macromol. Chem. Phys. 209(12), 1266-1273. DOI: 10.1002/macp.200800161

Chang, C., and Zhang, L. (2011). "Cellulose-based hydrogels: Present status and application prospects," Carbohyd. Polym. 84(1), 40-53. DOI: 10.1016/j.carbpol.2010.12.023

Chen, W., Zheng, R., Baade, P. D., Zhang, S., Zeng, H., Bray, F., Jemal, A., Yu, X. Q., and He, J. (2016). "Cancer statistics in China, 2015," CA-Cancer J. Clin. 66(2), 115-132. DOI: 10.3322/caac.21338

Fan, J., Li, T., Ren, Y., Qian, X., Wang, Q., Shen, J., and Ni, Y. (2017). "Interaction between two oppositely charged starches in an aqueous medium containing suspended mineral particles as a basis for the generation of cellulose-compatible composites," Ind. Crop. Prod. 97, 417-424. DOI: 10.1016/j.indcrop.2016.12.048

Fan, T., Li, M., Wu, X., Li, M., and Wu, Y. (2011). "Preparation of thermoresponsive and $\mathrm{pH}$-sensitivity polymer magnetic hydrogel nanospheres as anticancer drug carriers," Colloid. Surface. B 88(2), 593-600. DOI: 10.1016/j.colsurfb.2011.07.048

Faroongsarng, D., and Sukonrat, P. (2008). "Thermal behavior of water in the selected starch- and cellulose-based polymeric hydrogels," Int. J. Pharm, 352(1), 152-158. DOI: 10.1016/j.ijpharm.2007.10.022

Gao, Y., Wei, Z., Li, F., Yang, Z. M., Chen, Y. M., Zrinyi, M., and Osada, Y. (2014). "Synthesis of a morphology controllable Fe3O4 nanoparticle/hydrogel magnetic nanocomposite inspired by magnetotactic bacteria and its application in $\mathrm{H}_{2} \mathrm{O}_{2}$ detection," Green Chem. 16(3), 1255-1256. DOI: 10.1039/C3GC41535J

Huang, Y., Yu, H., and Xiao, C. (2007). "pH-sensitive cationic guar gum/poly (acrylic acid) polyelectrolyte hydrogels: Swelling and in vitro drug release," Carbohyd. Polym. 69(4), 774-783. DOI: 10.1016/j.carbpol.2007.02.016

Karaaslan, A. M., Tshabalala, M. A., and Buschlediller, G. (2010). "Wood hemicellulose/chitosan-based semi-interpenetrating network hydrogels: Mechanical, swelling and controlled drug release properties," BioResources 5(2), 1036-1054. DOI: 10.15376/biores.5.2.1036-1054

Korsmeyer, R. W., Gurny, R., Doelker, E., Buri, P., and Peppas, N. A. (1983). "Mechanisms of solute release from porous hydrophilic polymers," Int. J. Pharm. 15(1), 25-35. DOI: 10.1016/0378-5173(83)90064-9 
Li, X., Wu, W., and Liu, W. (2008). "Synthesis and properties of thermoresponsive guar gum/poly(n-isopropylacrylamide) interpenetrating polymer network hydrogels," Carbohyd. Polym. 71(3), 394-402. DOI:

10.1016/j.carbpol.2007.06.005

Liu, C., Wei, N., Wang, S., and Xu, Y. (2009). "Preparation and characterization superporous hydroxypropyl methylcellulose gel beads," Carbohyd. Polym. 78(1), 1-4. DOI: 10.1016/j.carbpol.2009.02.024

Liu, T. Y., Chen, S. Y., Lin, Y. L., and Liu, D. M. (2006a). "Synthesis and characterization of amphiphatic carboxymethyl-hexanoyl chitosan hydrogel: Water-retention ability and drug encapsulation," Langmuir 22(23), 9740-9745. DOI: $10.1021 / 1 \mathrm{a06} 1471 \mathrm{n}$

Liu, T. Y., Hu, S. H., Liu, K. H., Liu, D. M., and Chen, S. Y. (2006b). "Preparation and characterization of smart magnetic hydrogels and its use for drug release," J. Magn. Magn. Mater. 304(1), e397-e399. DOI: 10.1016/j.jmmm.2006.01.203

Nan, L., and Bai, R. (2005). "Copper adsorption on chitosan-cellulose hydrogel beads: Behaviors and mechanisms," Sep. Purif. Technol. 42(3), 237-247. DOI: 10.1016/j.seppur.2004.08.002

Nurunnabi, M., Parvez, K., Nafiujjaman, M., Revuri, V., Khan, H. A., Feng, X., and Lee, Y. (2015). "Bioapplication of graphene oxide derivatives: Drug/gene delivery, imaging, polymeric modification, toxicology, therapeutics and challenges," RSC Adv. 5(52), 42141-42161. DOI: 10.1039/c5ra04756k

O'Connor, S. M., and Gehrke, S. H. (2015). "Synthesis and characterization of thermally - responsive hydroxypropyl methylcellulose gel beads," Journal of Applied Polymer Science, 66(7), 1279-1290. DOI:10.1002/(SICI)10974628(19971114)66:73.0.CO;2-D

Qin, X., Lu, A., Cai, J., and Zhang, L. (2013). "Stability of inclusion complex formed by cellulose in naoh/urea aqueous solution at low temperature," Carbohyd. Polym. 92(2), 1315-1320. DOI: 10.1016/j.carbpol.2012.10.004

Rani, M., Agarwal, A., and Negi, Y. S. (2010). "Review: Chitosan based hydrogel polymeric beads - As drug delivery system," BioResources 5(4), 2765-2807. DOI: $10.15376 /$ biores.5.4.2765-2807

Salmawi, K. E. (2007). “Application of polyvinyl alcohol (PVA)/carboxymethyl cellulose (CMC) hydrogel produced by conventional crosslinking or by freezing and thawing," J. Macromol. Sci. A 44(6), 619-624. DOI: 10.1080/10601320701285045

Shaghaleh, H., Xu, X., and Wang, S. (2018). "Current progress in production of biopolymeric materials based on cellulose, cellulose nanofibers, and cellulose derivatives," $R S C A d v$. 8(2), 825-842. DOI: 10.1039/C7RA11157F

Sinha, V. R., and Kumria, R. (2001). "Polysaccharides in colon-specific drug delivery," Int. J. Pharm. 224(1), 19-38. DOI: 10.1016/S0378-5173(01)00720-7

Uekama, K., and Otagiri, M. (1987). "Cyclodextrins in drug carrier systems," Crit. Rev. Ther. Drug 3(1), 1-40. DOI: 10.1097/00002826-198710000-00013

Uhrich, K. E., Cannizzaro, S. M., Langer, R. S., and Shakesheff, K. M. (1999). "Polymeric systems for controlled drug release," Chem. Rev. 99(11), 31813198. DOI: $10.1021 / \mathrm{cr} 940351 \mathrm{u}$

Wang, K., Xu, X., Wang, Y., Yan, X., Guo, G., Huang, M., Luo, F., Zhao, X., Wei, Y., and Qian, Z. (2010). "Synthesis and characterization of poly(methoxyl 
ethylene glycol-caprolactone-co-methacrylic acid-co-poly(ethylene glycol) methyl ether methacrylate) $\mathrm{pH}$-sensitive hydrogel for delivery of dexamethasone," Int. J. Pharm. 389(1), 130-138. DOI: 10.1016/j.ijpharm.2010.01.026

Wang, L., Yu, Y., and Yao, W. (2017). "Preparation of nanocrystalline Fe3O4 and study on their adsorption performance for congo red," Inorg. Chem. Ind. 49(4), 37-40, 45.

Xu, J. Y., Yuan, T. Q., Xiao, L., and Sun, R. C. (2018). "Effect of ultrasonic time on the structural and physico-chemical properties of hemicelluloses from Eucalyptus grandis," Carbohyd. Polym. 195, 114. DOI: 10.1016/j.carbpol.2018.04.067

Yakup Arıca, M. (2015). "Immobilization of polyphenol oxidase on carboxymethylcellulose hydrogel beads: Preparation and characterization," Polym. Int. 49(7), 775-781. DOI: 10.1002/1097-0126(200007)49:7<775::AIDPI454>3.0.C

Article submitted: November 29, 2018; Peer review completed: March 13, 2019; Revised version received: March 13, 2019; Accepted: March 14, 2019; Published: March 19, 2019. DOI: $10.15376 /$ biores.14.2.3615-3629 